\title{
DESIGN, DEVELOPMENT AND EARLY TESTING OF A DEVICE FOR THE MONITORING OF ZOOTECHNICAL EFFLUENT DISTRIBUTION USING RAINGUN DISTRIBUTION SYSTEMS
}

\author{
Fabrizio Mazzetto, Aldo Calcante
}

\section{Introduction}

It is a fact that in the past few decades the increase in the number of head of cattle and the volume of manure produced has generated a marked imbalance between zootechnical load and tilled areas, therefore between the supply of fertilizers and the removal performed through crop absorption [Bassanino 2006]. As livestock farms evolve towards more highly specialised production methodologies and low-cost chemical fertilisers are made available on the market, the traditional connection between livestock manure and its agronomic application is weakening. Animal dejections are no longer the primary source of nutrients for crops but have become waste material to be disposed of at the lowest possible cost and with the lowest possible labour-intensive methods, by concentrating said disposal on limited areas, in the closest proximity to the zootechnical farms. This approach to the management of livestock manure, that fails to take into account the nature of the soil and the requirements of the crops, results in an excess of nutrients supplied in the fields under crop with the consequent pollution of the surface aquifer [Scotford 2001] that becomes therefore the final receptor of highly soluble chemical compounds (particularly nitrates) contained in the slurry. For these reasons the legislator has imposed restrictions on the maximum quantities of livestock manure to be spread [Provolo 2005], introducing the concept of territorial vulnerability to nitrogenous compounds, i.e. the identification of portions of territory that - for a number of reasons including marked soil permeability and the presence of significant polluting loads of industrial and zootechnical origin - need to be subject to limits to quantity of nitrogen to be distributed.

The restrictions imposed for less sensitive areas al-

Paper received 05.02.2008; accepted 14.01.2009

FABRizio MaZzeTto, associate professor; Aldo CALCANTE, researcher; Department of Agricultural Engineering, University of Milan; Via Celoria 2, 20133 Milan, Italy. E-mail: fabrizio.mazzetto@unimi.it low for a nitrogen load of $340 \mathrm{~kg} / \mathrm{ha}$, while the maximum load allowed in more exposed areas drops to $170 \mathrm{~kg} / \mathrm{ha}$. In order for compliance with such strict restrictions to be certain and verifiable it is necessary to rely on nitrogen flows monitoring systems from the cattle shed to the field [Sangiorgi 2005]. In this sense experiments have centred on the creation of low-cost systems based on GPS technology to monitor effluent distribution systems [Mazzetto 2006; Mazzetto 2007], as well as the definition of complete VRT systems for slurry tanks [Lanyon 1994; Morris 1999] and manure spreaders [Lague 2006]. No concrete proposals have so far been put forward with reference to large raingun distribution systems, even if such machines are often employed in the distribution of diluted swine and cattle manure $(<2 \%$ dry matter). These are systems for the distribution of large slurry volumes (generally comprised between 1000 and 2000 1/minute) with low operating costs, limited soil compaction and low energy requirements [Misselbrook 2004]. On the other hand, these distribution systems have considerable environmental and agronomical consequences (dispersion of ammonia in the atmosphere [Sommer 2001], emission of foul odours following manure atomisation, accumulation of heavy metals in the soil), particularly when the high volume that is normally spread exceeds the percolating capacity of the soil [Misselbrook 2002]. Nevertheless, the monitoring of such machines is performed today solely for irrigation purposes, with the aim of assisting farmers in their decision making (when and how much to irrigate) through the adoption of software and models available to farms and farmers' associations [Leib 2001; King 1999; Phene 1989]. The aim of this paper is to put forth and analyse the performance of a simplified system developed specifically to monitor the distribution of livestock manure using long-range sprinklers. The purpose is to integrate the main recorded distribution parameters (flow rate, range, quantity of distributed effluent) with the ones referring to operating times and the distance covered by the gun-supporting trolley (measured through a GPS receiver). The strength of such device resides in its autonomy from the point of view of energy, whereby 
the slurry flow in the pipe is used to generate, through a dynamo, an amount of electric power that enables the system to function.

\section{The MOSAICO project}

National literature offers a range of research studies aimed at defining rational methods for the distribution of livestock effluent according to environmentally sustainable criteria (consider, for example, the experience made in the frame work of the "Progetto Reflui", Law 95/95 - Environment Sector). Nevertheless, the aspect most closely related to direct monitoring of activities, that would allow for a final evaluation of the actions undertaken, are not investigated in such depth as are the objectives of preliminary (rational planning of activities [Sangiorgi 2003; Provolo 2003]) or operating checks (automated control of distribution flows, also based on site-specific approach [AA.VV. 2002; Balsari 2002; Balsari 2005; Mazzetto 2001]). The "MOSAICO" project, in the framework of which the experiences presented in this paper were carried out, is among the very first research efforts to meet territorial monitoring requirements of spreading operations through the observation in real time of the operations performed by using several automatic detection devices. The project stems from the collaboration between the Milan Institute of Agricultural Engineering and the Department of Agriculture and Environment of the Province of Modena with the main aim of finding monitoring solutions that would enable provincial officials to monitor - in a completely reliable and objective manner - the mode of distribution of zootechnical effluents in individual farms, according to the annual space and time limitations established by the provincial administration itself. To summarize, the devices adopted required the use of both positioning and identification technologies to ensure the operational monitoring (analysis of distance covered, with details on individual work phases), as well as environmental factors (estimate of slurry or manure flows across the territory). Such devices are ultimately based on the technology of the so-called Field Data Loggers (FDL) [Mazzetto 1997] that generally require the contextual adoption of a Management Information System (MIS that, in the case in point, needs to be integrated in a Territorial Information System, TIS, to allow for the centralized monitoring on the part of provincial officials) [Mazzetto 2005].

The FDL devices adopted were installed both in a tractor-oriented (tractor on-board device) and implement-oriented version (directly on the manure spreading operating machines). A number of specific problems arose in connection with the monitoring of distributing operations performed using raingun irrigation systems. These consist of a fixed reel umbilical system with travelling irrigator on self-winding hose. When in operation, the drum is connected (through the appropriate junction pits) to a distribution system consisting of an underground duct through which the effluent flows thanks to an independent pump, generally located near the slurry storage.

The features of such distribution systems are halfway between those of a mobile centre and a pivot irrigation units. Their specific functions require the double installation of the implement-oriented FDL so as to monitor the activation of the drum and of the distribution pump independently. The first FDL installed in this case consisted of: a) single-frequency GPS receiver and antenna (10 channels); b) data logger with $32 \mathrm{MB}$ MMC memory; c) lead battery, 12V24Ah; d) photovoltaic cells to maintain battery charge; e) system ignition through a vibration sensor located on the drive motors (drum and pump). It was not possible, however, to set up the FDL of the distribution systems in the immediate vicinity of the sprinkler because the level of smearing of organic material is - in general - such as to prevent a priori the use of photovoltaic cells. Therefore the following problems were encountered: a) difficulties in the definition of the distribution maps (only one fixed point can be monitored, without any indication as to the sprinkler paths); b) in case of prolonged nocturnal operation the power supply provided by the photovoltaic cell panel was unavailable; c) incoherence between the operating time of the drum engine (that keeps the FDL running through vibration) and the operating time of the pump located near the tanks. The shutting off of the latter did not always coincide with the shutting off of the drum engine, that was kept running - clearly, and very improperly, due to the negligence of the appointed staff - also for hours on end. In the light of such considerations, in addition to the need to tackle the issue of the costs of double installation, it was necessary to devise an alternative solution to ensure the direct monitoring of the displacement of the gun-supporting trolley.

\section{Materials and methods}

\subsection{Objectives}

The present paper presents a monitoring system for raingun distribution systems powered by a small turbine coupled to a dynamo that, by using the kinetic energy of the pressurized slurry flow, produces a direct voltage. This solution allows for the setting up of the FDL (with integrated GPS) in the proximity of the sprinkler and therefore the monitoring of its displacements in the field. Furthermore, as the system is powered directly by the flow inside the pipe, on/off time is regulated by the latter thus ensuring the correct measuring of real distribution time.

\subsection{The microturbine}

The prototype microturbine designed by the Milan Department of Agricultural Engineering is a power 
generator based on the concept of the vaned water wheel. In short, it consists of the components described below (Figure 1):

A) Casing: it represents the axial pressure pipe through which the fluid flows towards the impeller. It was obtained from a $10-\mathrm{mm}$ thick metal tube portion (diameter: $90 \mathrm{~mm}$, length: $300 \mathrm{~mm}$ ) suitably lathed on the inside to reduce roughness. Two coupling flanges are welded at the two ends to position the microturbine between the polyethylene pipe of the sprinkler and the sprinkler trolley.

B) Impeller: it is the wheel with horizontal axis consisting of a metal disk at the extremities of which 8 vanes are positioned that are slightly bent at their extremities so as to better intercept the flow. The impeller diameter is $200 \mathrm{~mm}$ : it was selected to enable the vanes to intercept the flow at its maximum speed points. The impeller is lodged inside a metal plate carter fixed, with bolts, to the body of the casing. This component was designed in order to meet future cleaning needs (slurry solid materials are expected to twine round the impeller that then must be easily accessible from the carter) rather than searching for an optimal high hydro-efficiency solution.

C) Mechanical junctions and supports: these are, respectively, the microturbine shaft connecting the impeller to the dynamo through a gear-wheeled transmission, and the ball bearing supports. In order to ensure that the parts not subject to contact with the fluid are watertight, each bearing is fitted with a pair of oil seals.

D) Motion drive system: it consists of a pair of gear wheels with a gear ratio of $\tau=5: 1$ (the band, fixed to the driving shaft, has 60 teeth, while the pinion, fixed to the dynamo spindle, has 12). This gear ratio represents a compromise between the number of revolutions that the dynamo has to complete to meet the electrical requirements of the monitoring system and the minimum mass flow rate of the fluid inside the pipe to overcome the resistance to rotation of the impeller.

E) Dynamo: it is a standard direct current motor (15 V - 1 A, 2000 rpm, loadless) used as voltage generator. Since the voltage produced depends on the number of revolutions of its armature and therefore, specifically, on the inconstant flow rate of the fluid inside the pipe, it is envisaged to adopt a D.C./D.C. converter that would ensure a stable $12 \mathrm{~V}$ output as required by the monitoring system. The dynamo and the motion drive system are lodged inside a steel box fixed to the carter.

\subsection{The monitoring system}

The FDL device monitoring effluent distribution using raingun distribution systems was designed to detect both the positioning of the gun sprinkler on the field, and the operating parameters required to calculate the range and flow rate of the slurry. The objective consists in returning, with good approximation, the treated area and the quantity of zootechnical effluent distributed. Based on the resulting mean values for each farm type it is then possible to identify the quantity of nitrogen and therefore to verify compliance with manure distribution restrictions.

The monitoring system is made up of the following devices (Figure 2).

a) A 12-channel single-frequency GPS receiver with integrated 16 Mbit (flash-type) built-in memory datalogger. The datalogger is fitted with two $0-12 \mathrm{~V}$ analog inputs and four 0-5V digital ones. Supply voltage is $12 \mathrm{~V}$ and maximum power input is approx. 0.3W. The GPS returns positioning data in NMEA 0183 format. An additional record enables
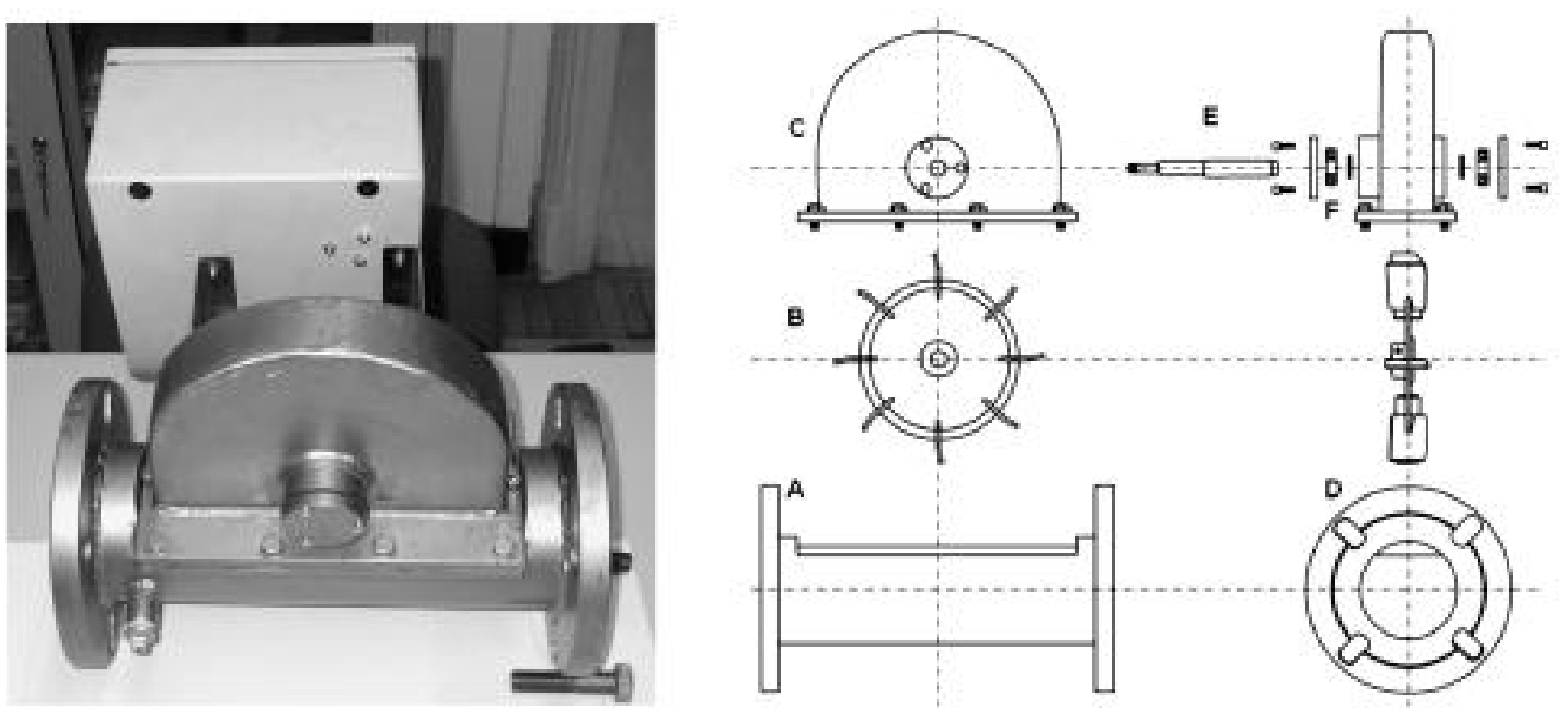

Fig. 1 - Photo and orthographic projection of the microturbine. The following parts can be identified: A) casing; B) impeller; C) carter; D) coupling flange; E) driving shaft, and F) ball bearing. 
memorizing analog and digital input levels. Recording time can be set ranging from 3 seconds to 3 minutes. The collected data is downloaded on a palm-top through a RS232 serial port.

b) A counter to measure the number of revolutions of the dynamo consisting of a tachymetric dynamo axially fixed to the shaft of the main dynamo.

c) A pressure transducer $(0 \div 1000 \mathrm{kPa})$ to measure the pressure inside the microturbine distributor.

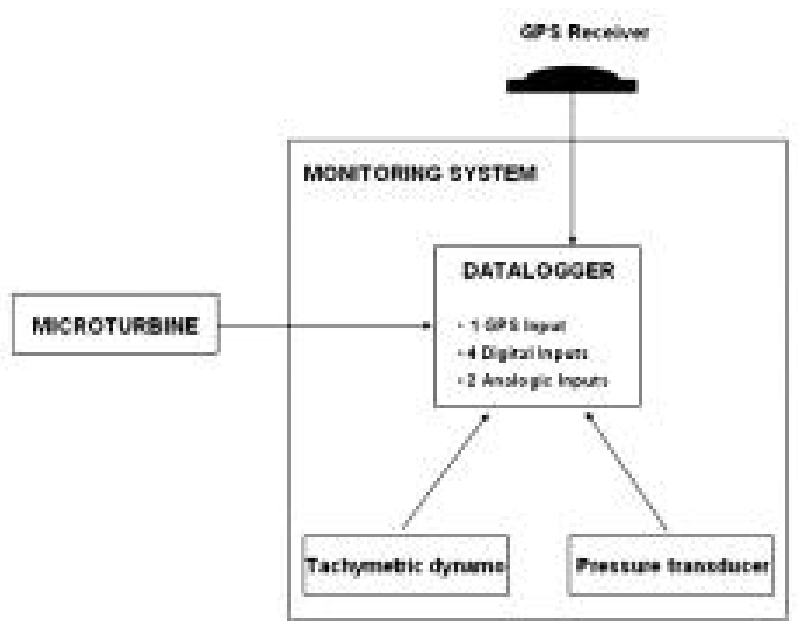

Fig. 2 - Block diagram of the monitoring system powered by the microturbine.

\subsection{The laboratory test}

A number of preliminary tests were carried out at the Laboratory of Hydraulic Engineering of the Milan Polytechnic with the purpose of testing the mechanical and electrical performance of the microturbine in controlled conditions. Specifically the following aspects were investigated: a) the variation of the number of revolutions of the dynamo based on the variation in the liquid flow rate and therefore the possibility to use the tachymetric dynamo for an estimate of instantaneous flow rate, and b) the capacity of the voltage source to provide the required electric supply to the datalogger in all operating conditions. In order to do so, measurements were made, at various increasing flow rate values, of the current and voltage at the ends of a changing load $R(\Omega)$ (Table 1$)$.

\begin{tabular}{|c|c|}
\hline THESIS & Load R $(\Omega)$ \\
\hline $\mathrm{T} 1$ & 5 \\
\hline $\mathrm{T} 2$ & 10 \\
\hline $\mathrm{T} 3$ & 15 \\
\hline $\mathrm{T} 4$ & 18 \\
\hline
\end{tabular}

TABLE 1 - The experimental tests performed on changing loads.
$R$ values were selected specifically to characterise the behaviour of the dynamo starting from non-optimal working conditions (high current absorption and low voltage drop on the load, Thesis T1) and moving towards less demanding working conditions (Theses T2, T3, T4). The aim was to test the capacity of the dynamo to supply power to the datalogger. In this sense it is acknowledged that for any electric machine the greater the $\mathrm{R}$ load compared to the value of the internal resistance of the electric motor, the fewer losses are recorded in the form of heat caused by excess power flowing through the armature. Therefore, in order to work with a very low $\mathrm{R}$ load - very close to the value of the internal resistance $R_{i}$ of the voltage generator $\left(\mathrm{R}<10 \mathrm{R}_{\mathrm{i}}\right)$ - an additional effort is required of the microturbine to overcome, not only the friction of the gear drive, but also the torque reaction $\mathrm{T}_{\mathrm{a}}$ (that depends ultimately on the load R), to which the resistance torque $T_{b}$ must be added to take into account Joule-induced losses in the generator. Indeed, the torque value $\mathrm{T}$ required to trigger the rotation of the axis of the turbine in the load conditions $\mathrm{R}$ examined is expressed by the following relation (1):

Where:

$$
\mathrm{T}=\mathrm{T}_{\mathrm{a}}+\mathrm{T}_{\mathrm{b}}
$$

$\mathrm{T}=$ driving torque required to trigger the rotation of the dynamo in normal conditions $(\mathrm{Nm})$;

$\mathrm{T}_{\mathrm{a}}=$ torque reaction opposing, to the rotation of the armature $(\mathrm{Nm})$, due to the law of conservation of energy;

$\mathrm{T}_{\mathrm{b}}=$ driving torque for Joule-induced friction and losses in winding $(\mathrm{Nm})$.

For the purposes of testing, the microturbine was connected in-line into a pipe (diameter: $120 \mathrm{~mm}$ ) in which the liquid was kept under pressure using recirculation pumps. The instantaneous flow rate (FR, 1/s), as recorded by an electromagnetic counter positioned upstream of the microturbine, was manually varied by operating a throttle valve located at the extremity of the pipe and in proximity of the draining shaft. The selected flow rate is almost identical to the one characterising the normal operating flow rate of raingun distribution systems (13-33 1/s), and each test was performed starting with a "closed valve" position to terminate with the partial opening of the valve.

Along with flow rate readings, other values were recorded including the number of dynamo revolutions, $r_{d}(\mathrm{rpm})$, using an analogical revolution counter and, for each load, the corresponding voltage and current values using a digital voltmeter and amperometer.

From a strictly theoretical point of view, considering the actual operating conditions, it would be necessary to recalculate the calibration function $F R=f\left(r_{d}\right)$ obtained in the laboratory, due to the varying viscosity of slurry compared to water. In actual fact, since the slurry generally distributed using raingun distribution systems is characterized by a dry matter content decidedly below $2 \%$, and given the degree of accuracy of the quantities measured with the FDL for the 
purpose of simple monitoring, any variations can be regarded as irrelevant.

\subsection{The field test}

In order to test the performance of the microturbine and the monitoring system in real operating conditions, a field test was carried out at the Az. A. Menozzi farm in Landriano (PV). In addition to proving the efficiency of the dynamo in real-life conditions, the test aimed at comparing the operating parameters measured directly in the field with the ones obtained from the recorded sensory data stored in the datalogger. The aim was to automatically estimate: a) the area that was interested by the actual distribution, based on the displacements of the gun-supporting trolley and the distribution range, and b) the quantities distributed based on the fluid flow rate in the pipe and the duration of the operation. In order to do so, the system was connected to the flange of the gun sprinkler of a raingun distribution system (the characteristics of which are outlined in Figure 3) and then activated by a pressurized flow.

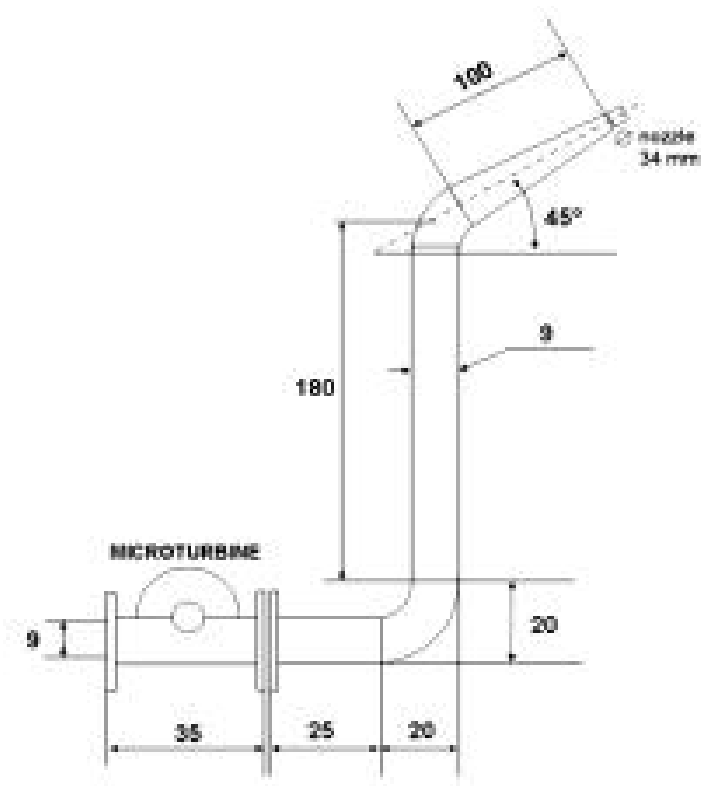

Fig. 3 - Dimensions (in $\mathrm{cm}$ ) of the gun sprinkler of the raingun distribution system used in the field test and particularly of the nozzle. Head loss regarded as significant in application of Bernoulli's theorem is due to the hairpin bend and the choke near the nozzle.

This first test required operating in very close proximity to the machine, therefore it was decided not to use zootechnical effluent but water collected from a farm irrigation canal that was put under pressure through a centrifugal pump activated by the pto of a tractor. The pipe of the distribution system was subsequently unreeled on the field for a total length of 240 meters and was reeled back onto the drum at constant speed $(0.028 \mathrm{~m} / \mathrm{s})$. With the aim of introducing a variability factor it was decided to modify - in the course of the testing - the flow rate of the fluid in the pipe.
Therefore, after reeling back 40 metres of hose, the number of revolutions of the tractor's pto - coupled to the centrifugal pump - was adjusted, thus defining two groups of tests at 350 and $400 \mathrm{rpm}$. The FDL of the monitoring system was set up so as to measure directly: a) the duration of the distribution and the distance covered by the gun-supporting trolley (using the GPS receiver, set to an acquisition frequency of 0.1 $\mathrm{Hz}$ ), b) the pressure $\mathrm{H}$ (in $\mathrm{m}$ of water column) in the microturbine distributor recorded downstream of the impeller using a pressure transducer, and c) the number of revolutions of the dynamo $r_{d}(r p m)$ using the tachymetric dynamo. In this way it was possible to calculate:

1. the flow rate FR (1/s) of the fluid distributed, based on the calibration function $-F R=f\left(r_{d}\right)$ - obtained in the course of laboratory testing;

2. the range $\mathrm{r}(\mathrm{m})$ as appraised with the practical formula (2) normally used in such contexts [Falciai 1981].

Such estimate is carried out based on the pressure values near the nozzle of the distribution system (comparable to parameter $\mathrm{H}$ measured by the FDL) after identifying the diameter $\mathrm{d}$ (in $\mathrm{mm}$ ) of the nozzle itself:

$$
\mathrm{r}=1.35 \cdot \sqrt{\mathrm{d} \cdot \mathrm{H}}
$$

The resulting range values were subsequently compared with the ones measured - every $10 \mathrm{~m}$, using a tape measure - directly in the field, while the verification of the resulting flow rate values was carried out by checking the operating parameters of each thesis with Bernoulli's theorem.

\section{Results and discussion}

\subsection{Results of the laboratory tests}

The results of the lab tests are presented in Table 2 . The table illustrates for each thesis, according to the experimental protocol summarized in Table 1, the following data: a) the flow rate FR values of the fluid as recorded by the electromagnetic counter, b) the rpm value $r_{d}$ of the dynamo, c) the voltage parameters $V$ (V), current intensity I (A) and power $\mathrm{P}(\mathrm{W})$ detected on the load. By comparing the four theses it appears that, also in the case of the lowest load resistance (thesis T1, Test No. 1) - i.e. in the conditions whereby the joule-induced losses in the armature are more significant - the friction caused by $\mathrm{T}_{\mathrm{a}}$ is not such as to critically influence the dynamo's rpm.

This means that the mechanical power generated inside the microturbine remains in excess (and is such as to satisfy, in any case, eq. (1)) also in more unfavourable conditions for the electric generator. An analysis of the power values on the loads selected for the various theses shows that it is possible to meet the electric requirements of the monitoring system (approx. 0.3 W) with a number of turbine revolutions of approximately $600 \mathrm{rpm}$ (Figure 4), corresponding 


\begin{tabular}{|c|c|c|c|c|c|c|}
\hline THESIS & No. Test & $\mathrm{FR}(1 / \mathrm{s})$ & $\mathrm{r}_{\mathrm{d}}(\mathrm{rpm})$ & $\mathrm{V}(\mathrm{V})$ & $\mathrm{I}(\mathrm{A})$ & $\mathrm{P}(\mathrm{W})$ \\
\hline \multirow{7}{*}{$(5 \Omega)$} & 1 & 13.5 & 575 & 1.09 & 0.20 & 0.22 \\
\hline & 2 & 19.1 & 1110 & 2.13 & 0.41 & 0.88 \\
\hline & 3 & 22.2 & 1330 & 2.44 & 0.49 & 1.19 \\
\hline & 4 & 24.1 & 1510 & 2.83 & 0.56 & 1.57 \\
\hline & 5 & 26.1 & 1755 & 3.22 & 0.64 & 2.07 \\
\hline & 6 & 29.2 & 1955 & 3.66 & 0.72 & 2.64 \\
\hline & 7 & 33.0 & 2410 & 4.44 & 0.88 & 3.89 \\
\hline \multirow{7}{*}{$(10 \Omega)$} & 8 & 12.4 & 590 & 1.55 & 0.16 & 0.24 \\
\hline & 9 & 19.7 & 1130 & 3.22 & 0.31 & 1.00 \\
\hline & 10 & 21.4 & 1400 & 3.80 & 0.37 & 1.39 \\
\hline & 11 & 26.1 & 1675 & 4.55 & 0.46 & 2.07 \\
\hline & 12 & 28.5 & 1900 & 5.28 & 0.53 & 2.82 \\
\hline & 13 & 30.7 & 2100 & 5.66 & 0.57 & 3.20 \\
\hline & 14 & 35.2 & 2520 & 6.75 & 0.69 & 4.64 \\
\hline \multirow{7}{*}{$(15 \Omega)$} & 15 & 12.1 & 600 & 1.98 & 0.13 & 0.26 \\
\hline & 16 & 21.3 & 1355 & 4.46 & 0.30 & 1.34 \\
\hline & 17 & 23.9 & 1565 & 5.28 & 0.34 & 1.82 \\
\hline & 18 & 27.2 & 1820 & 6.16 & 0.40 & 2.46 \\
\hline & 19 & 29.2 & 1990 & 6.66 & 0.44 & 2.96 \\
\hline & 20 & 30.7 & 2055 & 7.36 & 0.48 & 3.51 \\
\hline & 21 & 34.1 & 2470 & 8.21 & 0.54 & 4.47 \\
\hline \multirow{4}{*}{$\mathrm{T} 4$} & 22 & 15.0 & 800 & 3.27 & 0.18 & 0.58 \\
\hline & 23 & 17.5 & 1065 & 3.87 & 0.21 & 0.82 \\
\hline & 24 & 20.7 & 1320 & 4.72 & 0.26 & 1.20 \\
\hline & 25 & 24.8 & 1620 & 6.02 & 0.32 & 1.94 \\
\hline \multirow[t]{3}{*}{$(18 \Omega)$} & 26 & 28.7 & 1930 & 7.19 & 0.39 & 2.79 \\
\hline & 27 & 30.7 & 2140 & 7.90 & 0.42 & 3.33 \\
\hline & 28 & 33.5 & 2455 & 9.01 & 0.49 & 4.40 \\
\hline
\end{tabular}

TABLE 2 - The laboratory test results.

to liquid flow rates of around $800 \mathrm{l} / \mathrm{min}$. Furthermore, the variable nature of the voltage produced (which is a function of the liquid flow rate) points once again towards the need for a D.C./D.C. converter to stabilize the voltage generated by the dynamo and to increase it to the $12 \mathrm{~V}$ value as required by the datalogger.

Lastly, it was possible to prove that, with any load resistance greater than or - at most - equal to $5 \Omega$, the dynamo is able to generate constant electric power for similar flow rate values. As a consequence, it is possible, by positioning the measurements of the rate flow and dynamo rpm obtained experimentally on a single

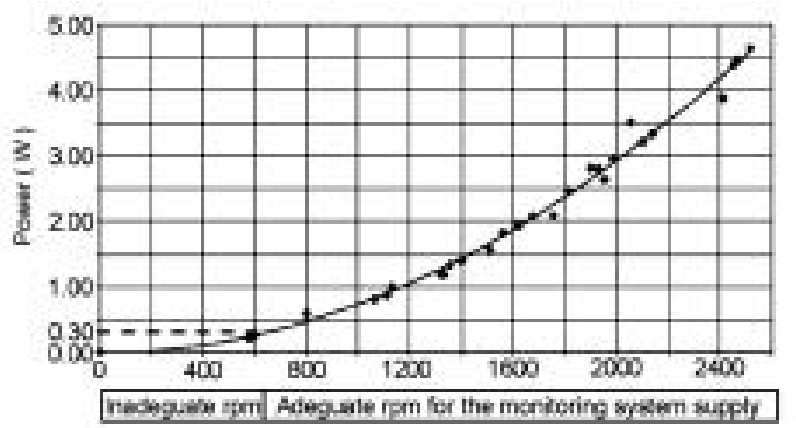

Fig. 4 - Rpm vs. power (W) diagram obtained with experimental values through lab testing. cartesian diagram, to identify the relation between the two quantities (Figure 5). Once the relation FR $=\mathrm{f}\left(\mathrm{r}_{\mathrm{d}}\right)$ is known, it is possible to perform an indirect measurement of the flow rate values based on the rpm value as recorded by the tachymetric dynamo.

The diagram in Figure 5 outlines the fact that the relation linking the number of revolutions of the dynamo $r_{d}$ to the flow rate $(1 / s)$ is of the linear type with a regression coefficient $\mathrm{R}^{2}=0.99$, in according to the turbo-machine theory. The corresponding calibration function is as follows (3):

$$
\mathrm{FR}(\mathrm{l} / \mathrm{s})=0.0116 \cdot \mathrm{rd}+6
$$

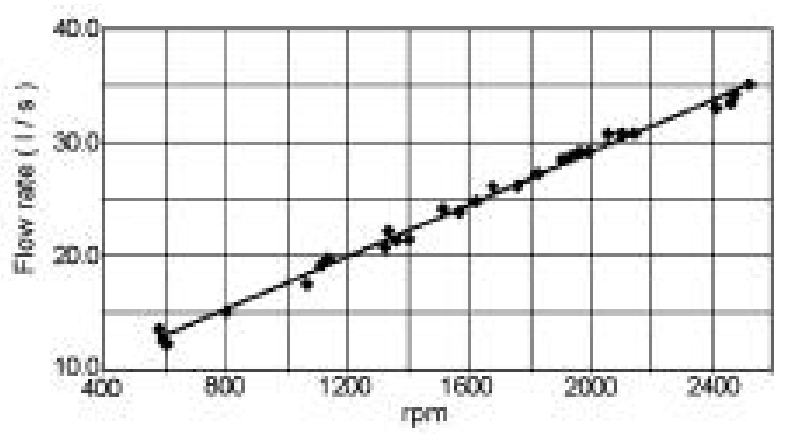

Fig. 5 - Rpm vs. flow rate (1/s) diagram obtained with experimental values from lab testing. 


\subsection{Results of the field test}

The results of the field test, carried out with the aim of evaluating the performance of the overall monitoring system in real operating conditions, are outlined in Table 3. It illustrates, for each experimental thesis, the mean values of: a) rpm of the dynamo and pressure in the microturbine distributor, both recorded by the FDL, b) two flow rate FR values, the former calculated with the calibration function obtained in the lab, the latter an estimate based on Bernoulli's theorem, c) two range $r$ values, the former calculated using the formula (2) and the latter measured in the field with tape measure.

The continuity equation (4) and the Bernoulli's theorem (5) applied to the experimental conditions are shown below:

$$
\begin{gathered}
\frac{\mathrm{v}_{\mathrm{A}}}{\mathrm{S}_{\mathrm{i}}}=\frac{\mathrm{v}_{\mathrm{B}}}{\mathrm{S}_{\mathrm{n}}} \\
\mathrm{z}_{\mathrm{i}}+\frac{\mathrm{v}_{\mathrm{h}}{ }^{2}}{2 \mathrm{~g}}+\frac{\mathrm{P}_{\mathrm{s}}}{\gamma}=\mathrm{z}_{\mathrm{s}}+\frac{\mathrm{v}_{\mathrm{s}}{ }^{2}}{2 \mathrm{~g}}+\frac{\mathrm{P}_{\mathrm{B}}}{\gamma}+\Sigma \lambda
\end{gathered}
$$

where:

$\mathrm{v}_{\mathrm{B}}=$ fluid flow speed over the nozzle $(\mathrm{m} / \mathrm{s}$, the unknown parameter to be determined);

$\mathrm{v}_{\mathrm{A}}=$ fluid flow speed after the impeller $(\mathrm{m} / \mathrm{s})$;

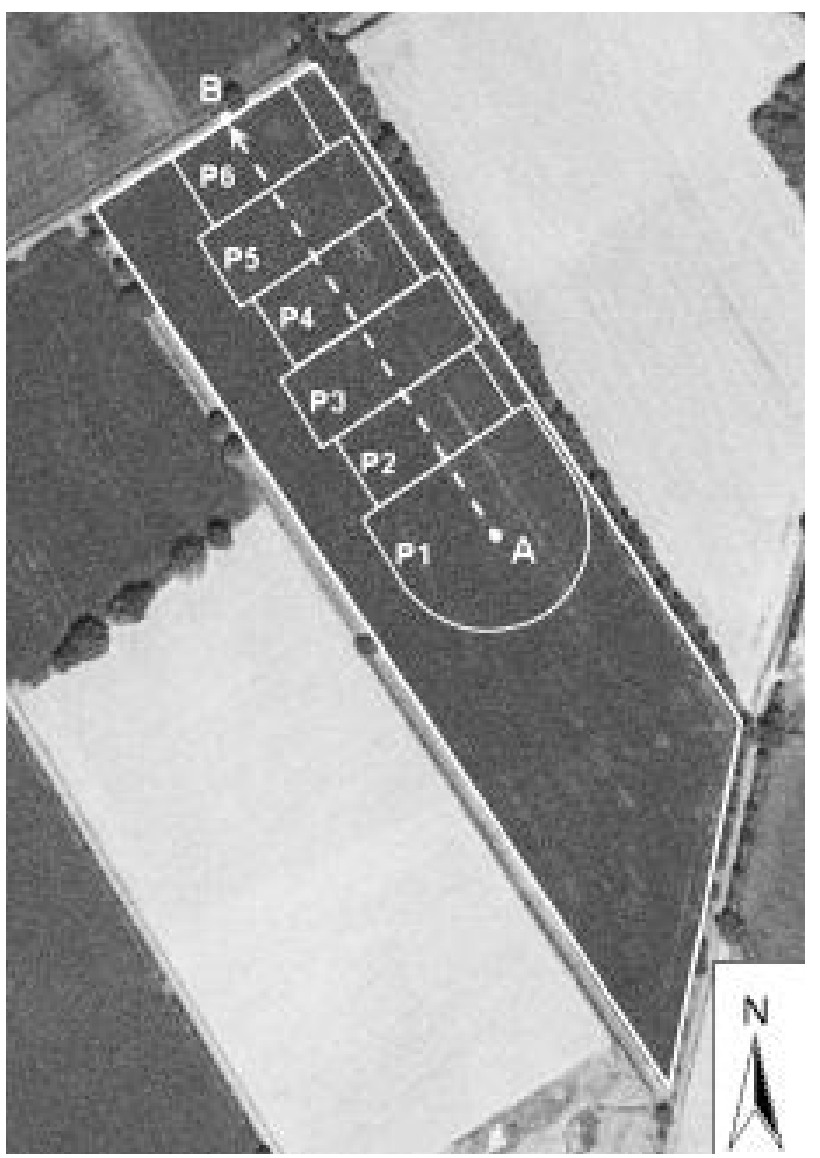

Fig. 6 - Digital map of the field test monitored with the proposed system. The arrow indicates the winding direction of the distribution hose.
$S_{B}=$ vertical section of the nozzle $\left(0.00091 \mathrm{~m}^{2}\right)$;

$\mathrm{S}_{\mathrm{A}}=$ vertical section of the polyethylene pipe $(0.0064$ $\left.\mathrm{m}^{2}\right)$

$\mathrm{z}_{\mathrm{A}}=$ geodetic head $(0 \mathrm{~m})$;

$\mathrm{P}_{\mathrm{A}}=$ pressure measured downstream of the impeller $(\mathrm{Pa})$;

$\mathrm{Z}_{\mathrm{B}}=$ head of the gun sprinkler $(2.5 \mathrm{~m})$;

$\mathrm{P}_{\mathrm{B}}=$ atmospheric pressure over the nozzle $(0 \mathrm{~Pa})$;

$\gamma=$ specific weight of the fluid $\left(\mathrm{N} / \mathrm{m}^{3}\right)$;

$\Sigma \lambda=$ minor head losses (m), (6):

$$
\Sigma \lambda=\left(k_{w r}+k_{i r}+k_{t a r}\right) \cdot \frac{v_{a}^{2}}{2 g}
$$

where $\mathrm{K}_{90^{\circ}}$ and $\mathrm{K}_{45^{\circ}}$ are typical values related to bends with gradual direction change equal to 0.15 and 0.14 respectively, and $\mathrm{K}_{\text {choke }}$ value is 0.5 (with $\mathrm{S}_{\mathrm{A}} / \mathrm{S}_{\mathrm{B}}$ >4) [AA.VV. 2003]. Head losses in the polyethylene pipe are considered negligible. The definitive flow rate value $\mathrm{FR}\left(\mathrm{m}^{3} / \mathrm{s}\right)$ is finally calculated as (7):

$$
\mathrm{FR}=\mathrm{V}_{\mathrm{B}} \cdot \mathrm{S}_{\mathrm{B}}
$$

The various theses differ, as previously mentioned, in the rpm value of the tractor's pto coupled to the centrifugal pump. It appears most evidently that the expected repeatability failed to be recorded between tests that are regarded as similar (P1, P2, P3 e P4, P5, $\mathrm{P6}$ ). This is however due to an irregular supply of water from the canal that entailed the discontinuous operation of the pump, thus introducing a further source of variability (not controllable) in the results of each experimental theses. As regards the flow rate, the difference between derived values and the values calculated with Bernoulli's theorem range from $0.3 \%$ (P3) to $2.9 \%(\mathrm{P} 4)$. As regards the range, deviation does not exceed $4.7 \%$ (P6). This proves that it is possible to use the dynamo's rpm value to calculate the flow rate and the pressure value to calculate the range, because both results are remarkably accurate for the purpose of operational and environmental monitoring of raingun distribution systems.

The results of the monitoring of the fertigation operation are presented in Table 4 and, are represented graphically in Figure 6.

When calculating the surface of the irrigated area, each thesis took into account also the semi-circular area described by the gun sprinkler that is highlighted only for thesis P1 in the digital spreading map in Figure 6. Working times, obtained through the GPS, are clearly in line with the results of contextual direct field observation.

This confirms that regulating the on/off mode of the FDL datalogger directly through the voltage generated by the microturbine can be an interesting solution to make monitoring more reliable and objective.

\section{Conclusions}

The present project focused on the creation, devel- 


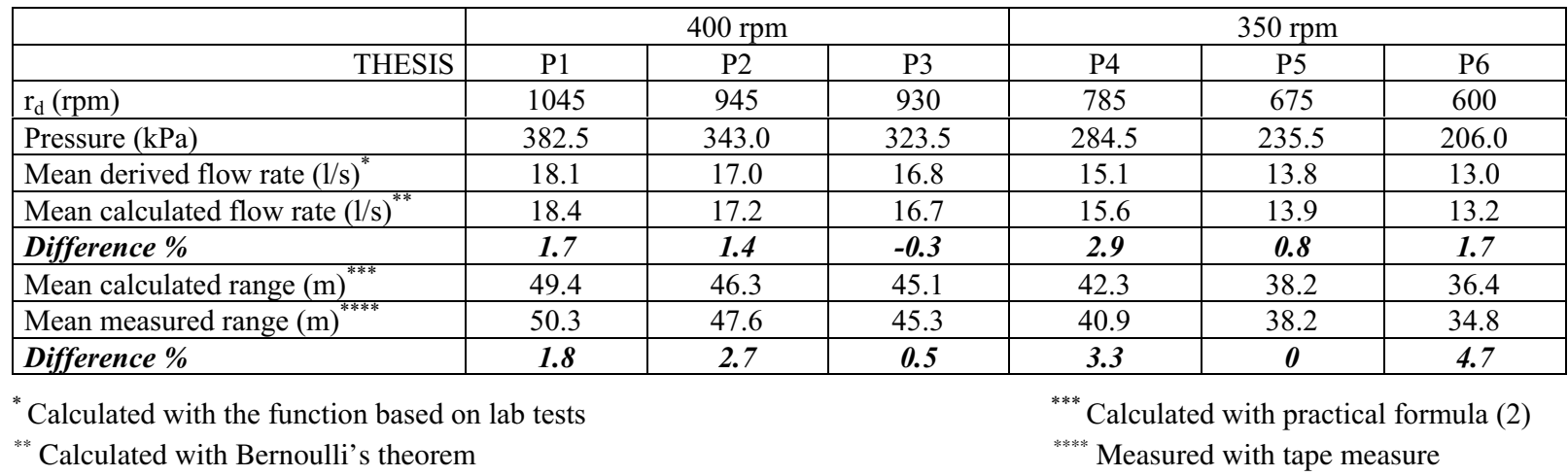

TABLE 3 - The results of the field test.

\begin{tabular}{|l|c|c|c|c|c|c|}
\hline \multicolumn{1}{|c|}{ THESIS } & \multicolumn{2}{|c|}{$400 \mathrm{rpm}$} & \multicolumn{2}{c|}{$350 \mathrm{rpm}$} \\
\hline & $\mathrm{P} 1$ & $\mathrm{P} 2$ & $\mathrm{P} 3$ & $\mathrm{P} 4$ & P5 & P6 \\
\hline Duration of operation (min) & 23.40 & 23.40 & 23.40 & 23.40 & 23.40 & 23.40 \\
\hline Treated field area $\left(\mathrm{m}^{2}\right)$ & 7785 & 7071 & 6803 & 6195 & 5348 & 4993 \\
\hline Distributed volume (m $\left.{ }^{3}\right)$ & 25.70 & 24.14 & 23.86 & 21.44 & 19.60 & 18.46 \\
\hline $\begin{array}{l}\text { Distributed volume per hectare } \\
\left(\mathrm{m}^{3} / \mathrm{ha}\right)\end{array}$ & 33.74 & 34.14 & 35.07 & 34.61 & 36.65 & 36.97 \\
\hline
\end{tabular}

TABLE 4 - The results of field test monitoring as calculated with the parameters recorded by the FDL.

opment and early testing of a device for the monitoring of the distribution of zootechnical effluents using raingun distribution systems with the aim of defining a system that is reliable and objective and useful both in farm management and to certify the activities carried out with respect to environmental regulations. The lab tests carried out at the Milan Polytechnic have led to the characterization of the performance of the power system based on a hydraulic microturbine

Subsequent field tests, while carried out for hygienic-practical reasons with water instead of diluted slurry, highlighted the potential of the system that, being directly powered by the flow of the fluid in the pipe, can be directly connected in proximity of the gun-supporting trolley, thus allowing for the measurement of its field displacements. The tests performed have proven the validity of the project also in terms of selection of quantities to be measured and their corresponding sensors: the values of dynamo rpm and pressure in the turbine distributor have proven more than adequate for the calculation, of the distribution flow rate and range, respectively. The possibility to implement a conductivity sensor for an estimate of the nutrients present in the slurry - an idea that has been envisaged and is currently being implemented - will enable the system to provide an estimate of the nitrogen distributed in the course of each distribution operation, thus ensuring a complete environmental monitoring in compliance with the regulations imposed by the legislator.

\section{Acknowledgements}

The authors wish to thank Prof. Enrico Orsi and the staff at Laboratorio Fantoli of the Milan Polytechnic for their assistance and active collaboration.

\section{References}

AA.VV., I reflui del sistema agricolo: le opportunità per i costruttori (The effluents produced by the agricultural system: opportunities for manufacturers). Proc. of III Technical Day organized by UNACOMA, Bologna, 2002, 18 november, 18-29.

AA.VV., Manuale dell'Ingegnere (Engineering Handbook). Vol. II, Hoepli, 2003, H-41.

Balsari P., Airoldi G., Gioelli F., Improved recycling of livestock slurries on maize by means of a modular tanker and spreader. Bioresource Technology, 2005, 96(2), 229-234.

Balsari P., Airoldi G., Gioelli F., Designing and realisation of an innovative slurry spreader. Proc. of International Conference on Agricultural Engineering, Budapest (H), 2002, 30 june- 4 july.

Bassanino M., Borrelli F., Grignani C., Sacco D., I reflui possono ridurre i costi di fertilizzazione (Effluent can reduce the costs of fertilization). L'informatore agrario, 2006, 62(26), 28-32.

Falciai M., Appunti di idraulica applicata (Applied Hydraulics Notes). CUSL, 1981.

King B.A., McCann I.R., Eberlein C.V., Stark J.C., Computer control system for spatially varied water and chemical application studies with continuous-move irri- 
gation systems. Computer and Electronics in Agriculture, 1999, 24(3), 177-194.

Lague C., Agnew J.M., Landry H., Roberge M., Iskra C., Development of a Precision Applicator for Solid and Semi-solid Manure. Applied Engineering in Agriculture, 2006, 22(3), 345-350.

Lanyon L.E., Dairy manure and plant nutrient management issues affecting water quality and the dairy industry. Journal of Dairy Science, 1994, 77(7), 1999-2007.

Leib B.G., Elliott T.V., Matthews G., WISE: a web-linked and producer oriented program for irrigation scheduling. Computer and Electronics in Agriculture, 2001, 33(1), $1-6$.

Mazzetto F., Bonera R., Calcante A., Landonio S., Salvi M., Sviluppo di un sistema ad architettura modulare per il controllo operativo delle macchine agricole nelle attività di campo (Development of a modular architecture for the agricultural machines control). Proc. Congress "Ingegneria Agraria per lo Sviluppo dei Paesi del Mediterraneo", Vieste del Gargano, 2001, 11-14 september.

Mazzetto F., Calcante A., Landonio S., Progetto MOSAICO: monitoraggio automatico dello spandimento dei reflui zootecnici ( The MOSAICO Project: automated monitoring of zootechnical effluents distribution). Proc. Congress "Ingegneria Agraria per lo Sviluppo dei Paesi del Mediterraneo", Catania, 2005, 27-30 giugno.

Mazzetto F., Calcante A., Salomoni F., A low- cost system for an automatic monitoring of slurry distribution activites: the MOSAICO project. Poster Paper Proc. "Precision Agriculture '07', Skiathos (GR), 2007, 3-6 june.

Mazzetto F., Calcante A., Salomoni F., Italian Experiences of Automatic Monitoring of Slurry Distribution Activities. Proc. World Congress - "Agricultural Engineering for a Better World", Bonn (D), 2006, 2-7 september.

Mazzetto F., Landonio S., Vaccaroni M., Farm activity information system based on automatic detection of machinery use. Proc. "Precision Agriculture '97", Warwick (UK), 1997, 7-10 September, 2, 911-920.

Misselbrook T.H., Smith K.A., Jackson D.R., Gilhespy S. L., Ammonia Emission from Irrigation of Diluite Pigs Slurries. Biosystems Engineering, 2004, 89(4), 473-484.

Misselbrook T.H., Smith K.A., Johnson R.A., Pain B.F., Slurry Application Techniques to reduce Ammonia Emissions: Results of some UK Field-scale Experiments. Biosystems Engineering, 2002, 81(3), 313-321.

Morris D.K., Ess D.R., Hawkins S.E., Parson S.D., Development of a site-specific application system for liquid animal manures. Applied Engineering in Agriculture, 1999, 15(6), 633-638.
Phene C.J., Techniques for computerized irrigation management. Computer and Electronics in Agriculture, 1989, 3(3), 189-208.

Provolo G., Manure management practices in Lombardy (Italy). Bioresource Technology, 2005, 96(2), 145-162.

Provolo G., La gestione aziendale dei reflui zootecnici (Management of zootechnical effluents). Quaderni de I Georgofili, "La Gestione dei reflui zootecnici fra problemi aziendali e territoriali", 2003, 2002(III), 9-25.

Sangiorgi F., Controllo totale della filiera per una corretta gestione dei reflui zootecnici (Managing animal wastes). Mondo Macchina, 2005, 14(9), 34-38.

Sangiorgi F., I reflui zootecnici: risorsa e problema (Zootechnical effluents: resource and problem). Quaderni de I Georgofili, "La Gestione dei reflui zootecnici fra problemi aziendali e territoriali", 2003, 2002(III), 9-25.

Scotford I.M., Cumby T.R., Inskip P.F., Improving the control and accuracy of slurry spreaders. Journal of Agricultural Engineering Research, 2001, 79(4), 139-149.

Sommer S.G., Hutchings N.J., Ammonia emission from filed applied manure and its reduction - invited paper. European Journal of Agronomy, 2001, 15(1), 1-15.

\section{SUMMARY}

The present project consisted in the design, development and early testing of a device for the monitoring of the distribution of zootechnical effluents using raingun distribution systems with the aim of defining a system that is reliable and objective that is useful both in farm management and to certify the activities carried out with respect to environmental regulations. The proposed system leads to the integration of the records of the main operating parameters of the distribution process (flow rate, range, quantity of distributed sewage) with those regarding operating times and distance covered by the gun-supporting trolley (measured through a GPS receiver). The main strength of said device lies in its autonomy in terms of power supply: the slurry flowing inside the pipe is used to generate, through a dynamo, an amount of electric power that is sufficient to ensure its operation.

Keywords: fertigation, raingun distribution system, microturbine, GPS, monitoring. 
002_Mazzetto(527)_09 3-09-2009 13:01 Pagina 18 